\title{
Methodology for assessing the prevalence of angina in primary care using practice based information in northern England
}

\author{
A Bottomley
}

\begin{abstract}
Objectives - The study aimed to consider the value of nitrate prescriptions issued by general practices as an indicator of coronary heart disease and to compare this with the use of coronary heart disease registers.

Design - The study was a cross sectional survey. A self completed questionnaire was used by general practices to indicate an age and gender breakdown of the total practice population, the number of patients taking nitrates, and details of patients recorded on a coronary heart disease register.

Subjects - All 48 general practices registered with Wakefield Family Health Services Authority were sent a questionnaire.

Main results - The prevalence of angina in the sample population of 164796 was $3.1 \%$. The prevalence of angina as assessed by coronary heart disease registers was significantly higher at $4.3 \%$.

Conclusions - Using questionnaires to assess how many patients are taking nitrates and therefore have angina may provide a quick, "snapshot" view of the prevalence of angina but the methodology is not a robust epidemiological tool. It is likely to provide errors in estimates of true prevalence and risks some under estimation when compared with coronary heart disease registers.
\end{abstract}

( $\mathcal{A}$ Epidemiol Community Health 1997;51:87-89)

Table 1 Population distribution (\%) in relation to age group and gender for the Wakefield Family Health Services Authority (FHSA) practices, pratctices with computerised records of patients prescribed nitrates, and practices with coronary heart disease (CHD) registers

\begin{tabular}{|c|c|c|c|}
\hline $\begin{array}{l}\text { Age group } \\
\text { (y) }\end{array}$ & $\begin{array}{l}\text { Wakefield FHSA } \\
\text { practices }=48 \\
(n=316000)\end{array}$ & $\begin{array}{l}\text { Nitrates } \\
\text { practices }=21 \\
(n=164000)\end{array}$ & $\begin{array}{l}\text { CHD } \\
\text { practices }=9 \\
(n=64000)\end{array}$ \\
\hline \multicolumn{4}{|l|}{$0-24$} \\
\hline Male & 16.6 & 16.1 & 15.0 \\
\hline \multicolumn{4}{|l|}{$25-44$} \\
\hline Male & 15.4 & 14.9 & 16.0 \\
\hline \multicolumn{4}{|l|}{$45-64$} \\
\hline Male & 10.8 & 11.1 & 12.1 \\
\hline $\begin{array}{c}\text { Female } \\
65-74\end{array}$ & 11.0 & 11.2 & 12.0 \\
\hline Male & 4.0 & 4.1 & 4.2 \\
\hline $\begin{array}{c}\text { Female } \\
75+\end{array}$ & 4.6 & 4.8 & 4.8 \\
\hline Male & 2.0 & 2.1 & 2.2 \\
\hline Female & 3.3 & 3.4 & 4.0 \\
\hline
\end{tabular}

Wakefield has a high mortality from coronary heart disease (CHD), with a standardised mortality ratio of 121 . Purchasing district health authorities now face the task of demonstrating effectiveness in achieving the Health of the $\mathrm{Na}$ tion targets by reducing morbidity and mortality from CHD. Health authorities also have the responsibility of ensuring that the services in their district match the demands of the prevalence of CHD. Deaths, however, are not a good measure of local services because of the very long lead time between health interventions and outcomes. This study sought an intermediate measure - angina - as an indicator of CHD morbidity.

The prevalence of angina is difficult to estimate. Attempts have been made to do so using both questionnaires and resting exercise electrocardiograms. These are of restricted use, however, due to methodological limitations, expense, and to the fact that they are typically focused on middle aged men. ${ }^{1}$ One study, ${ }^{2}$ using assessment methods similar to those noted above, examined angina in both men and women, but only those in the 40-59 years age group.

A more recent study ${ }^{3}$ assessed the prevalence of angina by examining prescriptions issued for nitrates from the prescription analysis and cost (PACT) information system. This seemed to be a valid way of estimating the prevalence of angina as nitrates are usually issued for the treatment of angina related to CHD and are seldom used to treat any disease other than angina. This study established that nitrates were $96 \%$ specific to angina. In particular, a positive benefit of this study was that it used routinely available data, which is less expensive than planned large scale surveys. The study limitation, however, was the finding of low sensitivity. Patients' records were used as the "gold standard", but when they were examined only $73 \%$ of those with angina had been correctly identified. This may have been an effect of several factors, such as the exclusion of some drugs commonly used to treat angina and the fact that the methodology is reliant upon patients' compliance in presenting the prescription to the pharmacists.

Given the limitations of the above study, ${ }^{3}$ the present study used information directly obtained from GPs' records, which were expected to provide more sensitive data and facilitate an alternative and repeatable method of assessing the prevalence of angina. Importantly, as a complete age and sex breakdown of angina 
Table 2 Practice characteristics: all those in the Wakefield Family Health Services Authority, practices with computerised prescribing records, and those with coronary heart disease (CHD) registers

\begin{tabular}{|c|c|c|c|}
\hline Charactersitics & All Wakefield & Nitrates & CHD registers \\
\hline $\begin{array}{l}\text { No } \\
\text { Single handed general practitioner } \\
\text { Fundholders } \\
\text { Computer systems in operation } \\
\text { Rural practice } \\
\text { Urban practice }\end{array}$ & $\begin{array}{r}48 \\
9 \\
17 \\
41 \\
3 \\
45\end{array}$ & $\begin{array}{r}21 \\
2 \\
6 \\
21 \\
2 \\
19\end{array}$ & $\begin{array}{l}9 \\
1 \\
5 \\
9 \\
0 \\
9\end{array}$ \\
\hline
\end{tabular}

Table 3 Patients prescribed nitrates in relation to age and gender

\begin{tabular}{|c|c|c|c|c|c|c|}
\hline \multirow[b]{2}{*}{ Age (y) } & \multicolumn{2}{|l|}{ Males } & \multicolumn{2}{|c|}{ Females } & \multicolumn{2}{|l|}{ Total } \\
\hline & No & $\%$ & No & $\%$ & No & $\%$ \\
\hline $0-24$ & 0 & 0 & 0 & 0 & 0 & 0 \\
\hline $25-34$ & 7 & 0.06 & 5 & 0.04 & 12 & 0.05 \\
\hline $35-44$ & 47 & 0.4 & 48 & C. 4 & 95 & 0.4 \\
\hline $45-54$ & 360 & 3.0 & 233 & 1.7 & 593 & 2.3 \\
\hline $55-64$ & 609 & 8.0 & 434 & 5.7 & 1043 & 6.8 \\
\hline $65-74$ & 956 & 14.2 & 832 & 10.5 & 1788 & 12.2 \\
\hline $75+$ & 620 & 17.2 & 980 & 15.3 & 1600 & 16.0 \\
\hline All ages & 2999 & 3.2 & 2532 & 3.0 & 5131 & 3.1 \\
\hline
\end{tabular}

(Percentage is expressed as a denominator of the total for specific age and sex band).

has never been investigated previously in a population sample, the study was intended to provide useful information on this.

\section{Method}

All 48 general practices registered with Wakefield Family Health Service Authority were sent a questionnaire asking for the number of people who regularly took nitrates (more than one prescription per year) in the previous year (January 1992 to 1993). Nitrates were defined as those preparations in Section 2.6.1 of the British National Formula (Number 23). Practices were also asked if they had a CHD register, and if so to provide details of the age and sex distribution of the register. Practice based denominators were used to provide practice population information.

\section{Results}

CHARACTERISTICS OF RESPONDER PRACTICES

Thirty eight $(79 \%)$ of the practices responded to the questionnaire. Seventeen of these practices could not easily identify the necessary information due to lack of resources (that is, repeat prescriptions were not computerised or there were staff shortages). The remaining 21 practices covered a patient population of 164796 , whose age and sex distributions were similar to those of the district (table 1).

Of these 21 practices, 12 indicated they had a CHD register and nine provided sufficient information from this for further analysis.
Those practices with a CHD register covered 67307 patients with an age and sex distribution similar to that of the district (table 1).

Table 2 indicates the characteristics of the responder practices, compared with the family health service authority as a whole. This indicates that rural practices were less likely to respond and those without computer systems were unable to do so. These practices were in the minority in Wakefield, but this was an important minority.

\section{PREVALENCE OF NITRATE PRESCRIPTIONS}

Altogether $3.1 \%$ of patients from the 21 general practices were regularly prescribed nitrates (table 3). Nitrates are rarely prescribed to patients below the age of 34 years. Those practices which indicated that they had prescribed nitrates to patients aged less than 34 were asked to verify this. Eight out of 12 cases were confirmed, two reflected inaccurate recording and in the remaining two it could not be determined whether these were errors or actual cases. It is not known if a similar error rate affects other age groups here, but obviously outlying values are more likely to be erroneous. After age 45 an increase is seen which reflects the natural history of the disease and national mortality figures.

COMPARISONS OF CHD REGISTERS AND NITRATES In the nine practices which had a CHD register and also nitrate records, a direct comparison was possible (table 4). Those nine practices with CHD registers indicated a lower nitrate percentage than the 21 practices as a whole. The figures for $\mathrm{CHD}$ registers in this subgroup are significantly above those recorded for nitrates $\left(\chi^{2}=17.42, \mathrm{p}<0.003\right)$, with this difference greater in men $\left(\chi^{2}=17.42, \mathrm{p}<0.003\right)$ than women $\left(\chi^{2}=12.63, \mathrm{p}<0.027\right)$. However, no verification exercise has been carried out to check the validity of these figures. It may well be that those practices with CHD registers are typically those interested in the disease and

Table 4 Prevalences* of patients prescribed nitrates and those on the practice coronary heart disease register in relation to age and gender

\begin{tabular}{|c|c|c|c|c|c|c|c|c|c|c|c|c|}
\hline \multirow[b]{2}{*}{ Age (y) } & \multicolumn{4}{|c|}{ Males } & \multicolumn{4}{|c|}{ Females } & \multicolumn{4}{|l|}{ Totals } \\
\hline & No & $\begin{array}{l}\text { Nitrates } \\
(\%)\end{array}$ & No & $\begin{array}{l}C H D \\
(\%)\end{array}$ & No & $\begin{array}{l}\text { Nitrates } \\
(\%)\end{array}$ & No & $\begin{array}{l}\text { CHD } \\
(\%)\end{array}$ & No & $\begin{array}{l}\text { Nitrates } \\
(\%)\end{array}$ & No & $\begin{array}{l}\text { CHD } \\
(\%)\end{array}$ \\
\hline $\begin{array}{l}0-34 \\
35-44 \\
45-54 \\
55-64 \\
65-74 \\
75+ \\
\text { All ages }\end{array}$ & $\begin{array}{r}0 \\
15 \\
101 \\
221 \\
329 \\
211 \\
877\end{array}$ & $\begin{array}{r}0.0 \\
0.3 \\
2.2 \\
6.2 \\
11.9 \\
14.5 \\
2.7\end{array}$ & $\begin{array}{r}6 \\
43 \\
192 \\
453 \\
544 \\
294 \\
1532\end{array}$ & $\begin{array}{r}0.0 \\
0.9 \\
4.2 \\
12.8 \\
19.5 \\
20.5 \\
4.6\end{array}$ & $\begin{array}{r}0 \\
11 \\
46 \\
145 \\
277 \\
334 \\
813\end{array}$ & $\begin{array}{r}0.0 \\
0.2 \\
0 \\
4.0 \\
8.6 \\
12.5 \\
2.4\end{array}$ & $\begin{array}{r}9 \\
23 \\
107 \\
268 \\
452 \\
502 \\
1361\end{array}$ & $\begin{array}{r}0.0 \\
0.5 \\
2.5 \\
7.5 \\
14.2 \\
19.0 \\
4.0\end{array}$ & $\begin{array}{r}0 \\
26 \\
147 \\
366 \\
606 \\
545 \\
1690\end{array}$ & $\begin{array}{r}0.0 \\
0.2 \\
1.6 \\
5.1 \\
10.1 \\
13.3 \\
2.5\end{array}$ & $\begin{array}{r}15 \\
66 \\
299 \\
721 \\
996 \\
796 \\
2893\end{array}$ & $\begin{array}{r}0.0 \\
0.6 \\
3.3 \\
10.1 \\
16.6 \\
19.5 \\
4.3\end{array}$ \\
\hline
\end{tabular}

* Percentage is expressed as denominator of the total for specific age and sex band. 
may well offer a number of alternative and effective strategies for the management of angina.

\section{Discussion}

The aim of the study was to determine the usefulness of assessing the prevalence of angina by using GPs' records of patients who are regularly taking nitrates. Given that these are predominantly prescribed only in the treatment of angina, ${ }^{3}$ this would indicate reasonable specificity (and seem a valid approach to adopt), particularly given that angina is correlated with standard mortality ratios for CHD. ${ }^{4}$ However, there are clearly limitations. Some people will be excluded from the analysis, in particular those who have angina but fail to consult their GP. One study, however, has suggested this number is small. ${ }^{2}$ The results are also reliant upon the GP correctly diagnosing and treating the angina. Furthermore, although the actual number of patients who comply with treatment was not examined in this study, it is important to note that patient compliance may be lower than actual repeat prescription use.

Additionally, when using GP records to assess regular nitrate use, it must be remembered that some nitrates are cheaper for patients to purchase directly from pharmacists than obtain on prescriptions. Given the methodology used, this may have contributed to an underestimate of the prevalence. This effect is difficult to estimate, but unless prescribing practices changed, one would expect this to remain consistent within a population sample. If future studies using the same approach were conducted, therefore, the error should be in the same magnitude.

CHD registers generally reported higher numbers than those receiving nitrates. The reason for this could include the fact that $\mathrm{CHD}$ records are more accurate in indicating the prevalence of CHD. Alternatively, the higher CHD rates may be due to errors in record keeping, changes in medical status of the patient, and no clear standardisation of criteria for eligibility for a CHD register. As an illustration, some practices may have patients recorded on the register if a family history is positive, while other practices may not. Also of importance are the changes in the medical status of patients, with some patients remaining on the CHD register after successful surgery.

The criteria for inclusion on CHD registers need to be agreed if they are to be used as indicators of prevalence of the condition.

Most practices which participated in the study indicated that data on nitrate prescription is not difficult to access. If this were a component of the new band 2 health promotion arrangements it would complement data obtained from CHD registers and act as an indicator of prescribing habits and practice policy.

The prevalence figures determined by this study are higher than those reported in Cannon's study in Nottingham, ${ }^{2}$ in which a total all age population of $1.5 \%$ was prescribed nitrates. As a comparison, when adjusted for different populations by age standardisation, this study showed a higher rate of $3.1 \%$. Whole population based figures have limited value as angina and mortality are age related. Cannon estimated that $2.6 \%$ of the population aged more than 30 had angina. The prevalence figure in this study for a similar lower age limit of 35 indicated that $5.8 \%$ of the sample had angina. This study would suggest it is more appropriate to use a higher age limit of 45 as few patients in the age band 35-44 years (only 95 from a total of $5135(0.05 \%)$ ) were prescribed nitrates. If this lower age limit is used, our prevalence figures for the sample indicate that $8 \%$ of people aged 45 years and over were recorded as taking nitrates for angina.

The prevalence figure for men aged 45-64 years was $5.1 \%$. This figure is greater than that of $4.8 \%$ reported in one study, ${ }^{1}$ yet lower than the $7.8 \%$ found in an earlier study. ${ }^{2}$ Reasons for the differences may relate to difficulties in comparisons of exact age ranges, geographical variations, and also the fact that $\mathrm{CHD}$ mortality, and presumably morbidity, has been declining nationally, especially over the 15 years spanned by these studies. ${ }^{5}$

The findings of this study need to be considered in the light of two limitations. Firstly, although past evidence ${ }^{3}$ has indicated that nitrates are a reliable and specific indicator of angina, no attempt was made to validate the sample specificity. This is most likely to produce errors in prevalence estimates. Secondly, there was considerable non-response. Over half $(56 \%)$ of the practices sent questionnaires were unable to provide information about nitrate prescriptions, and most ( $81 \%$ ) did not have any form of $\mathrm{CHD}$ register. This could have lead to a potential for bias that could only have been assessed adequately by examining all case records of the non-responder practices, which was not undertaken.

In summary, the use of GPs' prescription records for patients on regular nitrate therapy may be a useful "snapshot" tool in indicating the number of people affected by angina. However, this methodology may be prone to errors in prevalence estimates for the reasons noted. This approach gives lower figures than CHD registers but in the absence of agreed criteria for inclusion on registers it may be more reliable. The most obvious use of this methodology is in planning services and monitoring individual practice prescribing habits, but it may be less useful as an epidemiological tool than PACT information.

This study would not have been possible without the support of the general practices. I also thank Wakefield Health Authority, and in particular Gavin Illird, Colin Pollock, and Sally Pearson.

1 Shaper AG, Cook DG, Walker M, MacFarlane PW. Prevalence of ischaemic heart disease in middle aged British valence of ischaemic heart disease
men. Br Heart $\mathcal{F} 1984 ; 51: 595-605$.

2 Rose G, Ried DD, Hamilton PJS, McCartney P, Keen H, Jarrett RJ. Myocardial ischaemia, risk factors and death from coronary heart disease. Lancet 1977;i:105-9.

3 Cannon PJ, Connell PA, Stockley IH, Garner ST, Hampton JR. Prevalence of angina as assessed by a survey of prescriptions for nitrates. Lancet 1988;i:979-81.

4 Smith WCS, Kenicer MB, Tunstall-Pedoe H, Clark EC Crombie IK. Prevalence of coronary heart disease in Scotland: Scottish health study. Br Heart $\mathcal{F}$ 1990;64:295-8.

5 Simpson R, White A. Getting a handle on the prevalence of coronary heart disease. Br Heart $\mathcal{f}$ 1990;64:299-300. 